\title{
Characteristics of effective astronomer-educator partnerships in formal urban middle school science classrooms
}

\author{
Rommel J. Miranda, Jennifer E. Scott, and Karen G. Schaefer \\ Towson University, Department of Physics, Astronomy and Geosciences, 8000 York Road, Towson, \\ Maryland 21252, USA
}

(Received 12 May 2017; published 15 June 2018)

\begin{abstract}
[This paper is part of the Focused Collection on Astronomy Education Research.] This qualitative study investigates astronomers' and urban public middle school teachers' beliefs about the characteristics of effective outreach partnerships in formal science classroom settings. Twelve astronomers and twelve science teachers participating in Baltimore Project ASTRO, a NSF grant-funded astronomer-educator partnership outreach program, were interviewed after participation using semistructured, in-depth interview techniques. Constant comparative analysis was used to analyze the interview transcripts. The findings suggest that astronomers and urban public middle school teachers believe that the characteristics of effective outreach partnerships center on the following three themes: partnership collaboration, astronomer and teacher characteristics, and astronomer and teacher dispositions. Regarding partnership collaboration, astronomers and teachers believed that establishing a relationship; maintaining communication; planning, preparing, and facilitating lessons collaboratively; and following up on lessons taught and modifying lessons for future implementation were vital characteristics for effective astronomer-educator partnerships. Concerning astronomer and teacher characteristics, effective astronomer partners were described as being willing to volunteer their time, willing to provide resources, and willing to purchase supplies. Effective educator partners were characterized as being responsible for managing the classroom and students, differentiating lessons and activities, and administering pre- and postastronomy assessments to students before and after their astronomer partner visits. In reference to astronomer and teacher dispositions, effective astronomers were prompt, able to relate to kids, exited, passionate about what they do, knowledgeable, tolerant, and easy going. Effective teachers were committed, motivated to have a volunteer astronomer in their classroom, passionate about teaching and about their students, and knowledgeable about the astronomy curriculum. The findings of this study help to provide a more comprehensive understanding of the characteristics of effective astronomer-educator partnerships in formal urban middle school science classrooms and help to provide essential guidance to all who are interested in designing and facilitating such science educational outreach programming.
\end{abstract}

DOI: 10.1103/PhysRevPhysEducRes.14.010147

\section{INTRODUCTION}

Empirical studies reveal that science outreach programs can help to improve the science content knowledge of students in the general student population, including students in urban public-school settings [1,2]. Over the past two decades, scientist-educator partnership programs have rapidly emerged across the U.S. with the goal of enhancing the teaching and learning of science. Reports suggest that $\mathrm{K}-12$ science education and scientific literacy could be strengthened if scientists partner with teachers in

Published by the American Physical Society under the terms of the Creative Commons Attribution 4.0 International license. Further distribution of this work must maintain attribution to the author(s) and the published article's title, journal citation, and DOI. schools to share their knowledge, passion, and expertise with students [3-5]. Although published reports often describe the outcomes of scientist-educator partnership programs anecdotally, studies about what constitutes effective outreach partnerships have not been well documented in the extant research literature. Thus, a more comprehensive understanding of the characteristics of effective scientist-educator partnerships is vital, especially for designers and facilitators of such science educational outreach programming. Accordingly, this NSF grantfunded empirical study examines the following qualitative grand tour research question: What do astronomers and teachers believe to be the characteristics of effective astronomer-educator partnerships in formal urban middle school settings? To provide context to the study, the background and role of the authors are as follows: R. M. is a science education professor and researcher and a codirector of Baltimore Project ASTRO since 2008; J. S. is an 
astronomy professor and a co-director of Baltimore Project ASTRO since 2008; and K. S. is a professional astrophysicist and the program coordinator of Baltimore Project ASTRO since 2013.

\section{THEORETICAL FRAMEWORK}

This study is framed within a well-established body of research on beliefs [6-9]. Beliefs are a group of related constructs (e.g., attitudes, perceptions, conceptions, and dispositions) that exert powerful influences on behavior [10]. Bryan and Atwater suggest that "beliefs are part of a group of constructs that describe the structure and content of a person's thinking that are presumed to drive his/her actions" [11]. Thus, it is this relationship between belief and behavior that makes the study of scientists' and teachers' beliefs so critical to an understanding of educational outcomes. This study is also situated within research that centers on teacher beliefs about student science learner characteristics and classroom practice. Herwitz and Guerra suggest that teachers generally view science as a fixed, somewhat daunting, body of knowledge [12]. Consequently, the content of science curricula is often perceived by teachers, especially in urban school settings, as reserved for the elite few $[13,14]$. Research suggests that teachers believe that the student characteristics that are necessary for high achievement in astronomy include specific cognitive skills, dispositions, and prior knowledge and experiences with the subject area [14]. Miranda found that teachers further view their own students as largely lacking in these characteristics and report such instructional modifications as not teaching the prescribed astronomy curriculum, deemphasizing related mathematics, reading and science process skill sets, deemphasizing advanced astronomy topics and laboratory experiences, and reducing the depth of astronomy concepts [14]. However, research shows that scientist-educator partnerships can affect change in teacher beliefs and associated values in science [15] and classroom practices [12]. Luehman and Markowitz confirm that carefully designed collaborative out-of-school inquiry programs have the potential to broaden students' experiences of science, especially those from under-resourced schools, as well as bridge them to school science [1]. Other empirically based studies reveal that urban public middle school teachers believed that their partnership with an astronomer largely influenced their students' level of motivation, increased their students' level of questioning, and enhanced their students' learning experiences in astronomy by making the subject area more realistic, relevant, and scientifically rigorous $[2,14]$. Research studies further suggest that teachers believed that their partnership with an astronomer positively influenced their students' behaviors and attitudes toward science $[2,16]$. Keeping in line with this area of research, the present study examines astronomers' and teachers' beliefs about the characteristics of effective outreach partnerships in formal urban middle school science classrooms.

\section{METHODOLOGY}

\section{A. Setting}

Project ASTRO is a program run by the Astronomical Society of the Pacific since 1994 to link professional and amateur astronomers with local $\mathrm{K}-12$ teachers and students and to bring inquiry-based astronomy activities to classrooms. In this program, an educator is paired with an astronomer who is willing to volunteer their time to coteach astronomy activities in one of their classes. The astronomer commits to visiting the educator's classroom at least four times during the academic school year. Both astronomers and educators receive a copy of the Universe at Your Fingertips DVD. The DVD was developed by the Astronomical Society of the Pacific and includes 133 fieldtested hands-on activities, from programs and projects around the United States. Additionally, astronomer partners are provided with a $\$ 100.00$ materials stipend to purchase supplies for activities that they would implement with their educator partners in their classrooms.

Project ASTRO has been touted as a successful model for astronomer-educator partnerships [17] and has been listed among the most effective outreach partnership programs in the United States involving scientists and engineers in K-12 education [18]. Teachers participating in Project ASTRO have indicated that their astronomer partners positively influenced their students' attitudes toward science $[2,16]$. Local Project ASTRO networks currently operate in 19 regions throughout the United States. However, the Baltimore Project ASTRO site utilized in this study is unique because it specifically focuses its astronomy education outreach effort within a large urban school district. Baltimore Project ASTRO currently supports approximately 50 astronomer-educator partnerships.

\section{B. Study participants}

Maximum variation sampling is a technique used to select a broad range of information-rich participants [19]. Accordingly, a maximum variation sample of research participants was used in this study to ensure a diversity of views. Twelve astronomers and twelve public middle school science teachers were recruited and voluntarily agreed to participate in the study. Table I provides profiles of the urban public middle school science teacher participants with respect to their gender, educational level, school achievement level, grade level taught, and years of teaching experience. The teachers participating in the study also did not have any prior experience collaborating with a scientist or astronomer in their classroom. To ensure anonymity, Table II provides basic profiles of the astronomer participants with respect to gender, and whether or not they had prior outreach experience. Additionally, to further ensure the anonymity of study participants, the middle school teachers listed in Table I and the astronomers listed in Table II were not matched partners. The group of 
TABLE I. Middle school teacher participant profiles.

\begin{tabular}{|c|c|c|c|c|c|}
\hline $\begin{array}{l}\text { Teacher } \\
\text { number }\end{array}$ & Gender & $\begin{array}{l}\text { Educational } \\
\text { level }\end{array}$ & $\begin{array}{c}\text { School achievement } \\
\text { level }\end{array}$ & $\begin{array}{l}\text { Grade level } \\
\text { taught }\end{array}$ & $\begin{array}{l}\text { Teaching } \\
\text { experience }\end{array}$ \\
\hline 1 & Male & B.S. Geology; M.S. Systems Management & Low & 6 and 8 & 10 years \\
\hline 2 & Female & B.S. Biology & Low & 6 & 4 years \\
\hline 3 & Female & B.S. Physics; M.Ed. Administration and Supervision & Low & 7 and 8 & 4 years \\
\hline 4 & Female & B.S. Chemistry & Low & 8 & 21 years \\
\hline 5 & Male & B.S. Finance & Middle & 6 & 2 years \\
\hline 6 & Female & B.S. Biology; B.A. Psychology & Middle & 7 and 8 & 2 years \\
\hline 7 & Female & B.S. Elementary Education; M.A. Special Education & Middle & 6 & 3 years \\
\hline 8 & Male & B.S. Special Education; M.A. Special Education & Middle & 7 and 8 & 3 years \\
\hline 9 & Female & B.S. Biology; M.Ed. Curriculum and Instruction & High & 6 and 8 & 10 years \\
\hline 10 & Male & B.S. Physics; M.Ed. Curriculum and Instruction & High & 6 and 8 & 32 years \\
\hline 11 & Female & B.S. Biology & High & 6 and 8 & 3 years \\
\hline 12 & Female & B.S. Chemistry & High & 7 and 8 & 2 years \\
\hline
\end{tabular}

astronomers participating in the study ranged from professional astronomers, university astronomy professors, and amateur astronomers from local astronomical societies. Teacher participants were from public middle schools representing a range of achievement levels in a large urban school district. Four teachers were from high-achieving schools, four teachers were from middleachieving schools, and four teachers were from lowachieving schools as defined by the state's school performance report achievement data. All middle school grade levels were represented. The percentage of nonWhite students enrolled in the schools ranged from $77.5 \%$ to $96.3 \%$. The percentage of classes not taught by highly qualified teachers ranged from $35.0 \%$ to $59.4 \%$. The percentage of teachers who possessed alternative or provisional teaching certification ranged from $24 \%$ to $46.9 \%$. The percentage of students eligible for free or reduced lunch ranged from $31 \%$ to $69.2 \%$. The percentage of students passing the state middle school assessment in science ranged from $15.7 \%$ to $90.2 \%$. The percentage of students with an individualized education plan (IEP) ranged from $1.0 \%$ to $18.6 \%$.

TABLE II. Astronomer partner profiles.

\begin{tabular}{lcc}
\hline \hline Astronomer number & Gender & Prior outreach experience \\
\hline 1 & Male & Yes \\
2 & Female & Yes \\
3 & Male & Yes \\
4 & Male & No \\
5 & Male & Yes \\
6 & Female & No \\
7 & Male & Yes \\
8 & Female & No \\
9 & Male & Yes \\
10 & Male & Yes \\
11 & Male & No \\
12 & Male & No \\
\hline \hline
\end{tabular}

\section{Grand tour research question}

This qualitative study was designed to answer the following grand tour research question: What do astronomers and teachers believe to be the characteristics of effective astronomer-educator partnerships in formal urban middle school settings? The use of a grand tour question is appropriate for this study because it encourages the interviewee to open up and talk about their experiences, to describe how things usually are, and to generalize and talk about pattern of events [20]. Qualitative researchers often begin interviews with a grand tour research question. Grand tour research questions are open-ended questions that allow the interviewee to set the direction of the interview. The interviewer then follows the leads that the interviewee provides. The interviewer can always return to their preplanned semistructured interview guide questions after the leads have been followed.

\section{Data collection}

Data were collected through the use of a grand tour research question and a semistructured interview guide. Each participant was interviewed two weeks following their participation in Baltimore Project ASTRO. Prior to the beginning of the study, the researcher (first author) contacted and visited all study participants for the purpose of building rapport and trust, removing any perceived status differences between the researcher and participant. Once rapport and trust were established with a study participant, a postparticipation interview was scheduled and conducted at a site that was most convenient for that participant. Each participant was interviewed by the researcher using the grand tour research question and semistructured interview guide. The three preplanned questions on the semistructured interview guide were specifically formulated to incite participants to reflect on their own experiences. However, the researcher asked probing questions as needed to clarify participants' meanings and, where relevant, to ask participants for 
concrete examples to substantiate their espoused beliefs. Following is the semistructured interview guide:

(1) What do you believe are the characteristics of an effective partnership?

(2) Please describe your Project ASTRO partnership and how you interacted with your Project ASTRO partner during the academic school year.

(3) Please describe an activity that you and your Project ASTRO partner facilitated with students.

Terms used in the semistructured interview guide were defined and clarified for the study participants to ensure that they understood the context in which the questions and words were being used. Each interview lasted approximately one hour. All interviews were audiotaped and transcribed verbatim.

\section{E. Data analysis}

Constant comparative analysis, as described by Corbin and Strauss [21], was used by the researcher (first author) to analyze the interview transcripts to seek patterns in the data. These patterns were then arranged in relationship to each other in order to develop characterizations of astronomers' and educators' beliefs.

More specifically, this analytic process was based on immersion in the data and began with open coding. This involved the examination of minute sections of text made up of individual words, phrases, and sentences. Descriptive codes were assigned to these sections of text. These codes were systematically compared and contrasted, merged into new concepts, and eventually renamed, yielding increasingly complex and inclusive categories. Corbin and Strauss [21] described open coding as that which "fractures the data and allows one to identify some categories, their properties and dimensional locations" (p. 97). Open coding was followed by selective coding, which was the process of selecting the core category, systematically relating it to other categories, validating those relationships by searching for confirming and disconfirming examples, and filling in categories that needed further refinement [21].

In this study, relationships between core categories were sought and tested both within and across transcripts. Codes and categories were also sorted, compared, and contrasted until analysis produced no new codes or categories, and when all of the data were accounted for in the core categories. Criteria for core status were (a) a category's centrality in relation to other categories, (b) frequency of a category's occurrence in the data, (c) a category's inclusiveness and the ease with which it related to other categories, (d) clarity of a category's implications, and (e) its allowance for maximum variation.

The themes that emerged from the data were formulated in relation to the study's grand tour research question. Throughout the analysis, the input, reflections, and feedback of all study participants, as well as the co-director of the program (second author) and the program coordinator (third author) were sought to ensure the trustworthiness of the data and authenticity of the interpretation of the data. Data collection and analysis occurred concurrently, with the results of early analyses being used to inform subsequent data collection.

\section{FINDINGS}

In addressing the study's grand tour research question, there were a number of characteristics that astronomers and middle school teachers believed to be essential for effective astronomer-educator partnerships in formal urban middle school science classrooms. The themes that emerged from the data can be categorized into three groups: partnership collaboration; astronomer and teacher characteristics, and astronomer and teacher dispositions.

\section{A. Partnership collaboration}

Astronomers and middle school science teachers believed that establishing a relationship and maintaining communication were important characteristics for effective astronomer-educator partnerships. For instance, Astronomer 3 expressed that "getting to know each other is probably the most important thing for having a successful partnership" and remarked that he developed a "genuine friendship" with his educator partner. Regarding maintaining communication, Teacher 2 articulated that "in order for this [partnership] to work, we're going to have to stay in contact. I don't see how you could possibly do this without communicating with your partner." In a similar manner, Astronomer 7 believed that "it is important that partnerships establish communication right from the beginning" and described a negative experience which reinforced the importance of communication, "We really can't have any of this, okay it's been a fun workshop, I'll call you, and then they never call back." Astronomers and middle school science teachers also believed that successful astronomereducator partnerships maintained communication with each other through telephone calls, email, or social media (i.e., Facebook). For example, Teacher 1 mentioned that he "talked probably four times before he came to the classroom," while Astronomer 12 said that his educator partner would simply "call me, or I would call her" to discuss astronomy activities they planned on doing with students. Conversely, Astronomer 4 voiced having communication issues with their educator partner and revealed, "I find that it has been me motivating the contact, rather than the teacher."

Astronomers and middle school science teachers frequently mentioned that planning, preparing, and facilitating lessons collaboratively were vital characteristics for effective astronomer-educator partnerships. For instance, Teacher 12 indicated, "We would sit down and we would plan in advance the activities they were going to do." In a similar manner, Astronomer 2 stated, "We picked out a couple of activities from Universe at Your Fingertips that 
we wanted to refine and do with the class." Astronomer 11 also remarked, "She and I met at the beginning of the semester and she'll say these are the things that I want to cover." Astronomers and middle school science teachers also acknowledged that effective astronomer-educator partnerships took the time to make astronomy activities relevant to students. For example, Astronomer 8 expressed, "She taught chemistry rather than astronomy, so I did comets, where you could talk about the chemistry of a comet." Likewise, Teacher 11 articulated about how their astronomer partner made an astronomy activity culturally relevant for students, "He talked about the constellations according to African tribes and different tribes." Astronomers and middle school science teachers further described that effective partnerships scheduled classroom visits ahead of time and would have discussions about materials they would need to facilitate astronomy activities. For instance, Astronomer 9 explained, "If we schedule far enough ahead, it's usually easy enough to do." In the same manner, Astronomer 6 conveyed, "One thing that my teacher was really good at from the beginning is that she had sort of an idea of what her lesson plan was going to be throughout the whole semester. So, I could actually plan out the visits from the beginning of the year which was kind of helpful to me because it allowed me as an astronomer to plan out my schedule in terms of what days I was going to effectively give up." Similarly, Teacher 7 commented, "We talked a week before the lesson was taught so that we could make sure that we had everything that we needed. We would have a checklist of supplies that we needed, such as dry ice, gloves, trash bags, bowls and things like that." Conversely, Astronomer 4 articulated about having issues regarding planning activities with their educator partner, “The prep time was something I didn't quite expect or anticipate. I sort of did all the background, all the prep work for everything." Regarding facilitating lesson plans collaboratively, Teacher 9 cited, "We are co-teaching, so it wasn't really like I am going to just hand over the class to the astronomer." However, in stark contrast, Astronomer 4 explained issues he had when facilitating an astronomy activity, "My educator partner felt she could leave me for considerable periods of time. I was worried at one point that she wasn't going to make it back in before the end of class, and I had no idea how to handle the interclass transition."

Astronomers and middle school science teachers believed that following up on lessons taught and modifying lessons for future implementation were essential characteristics for effective astronomer-educator partnerships. For example, Astronomer 3 explained, "We'll usually follow up within a week or ten days after a visit and just discuss, well this aspect went well or, you know, we might try it another way, or next time maybe we'll use less dry ice, or something to that extent." Discussing the importance of lesson modification, Teacher 10 expressed, "When we did the comet activity, the first class we had, we had every single kid build one, and that turned out to be a little bit too much and hard to get it all done with that many kids doing it all at once. We cut back on like, you know big groups of kids for the rest of the day and that worked perfectly." Similarly, Astronomer 5 stated, "We try to make astronomy activities work better for the kids."

\section{B. Astronomer and teacher characteristics}

Teachers described many characteristics of effective astronomer partners. Several teachers expressed that their astronomer partners were always willing to volunteer their time. For example, Teacher 3 remarked, "He comes in more than he is supposed to." Other teachers similarly mentioned that their astronomer partners would judge science fairs, stay for several class periods, meet during the evening to show students stars with a telescope or host a star party, and do several activities throughout the day with students. Almost half of the teachers also remarked that their astronomer partners were willing to provide resources for students, such as rockets kits for kids during space week, DVDs, posters, postcards, bookmarks, pamphlets, magazine subscriptions, and astronomy images. Astronomers were further willing to purchase supplies for Project ASTRO activities. For instance, Astronomer 1 explained, "It seems to me that as the astronomer, I would take the initiative to get whatever materials it is for the activities that I am going to run or going to do rather than asking the teacher to pick up everything else. The astronomer is probably going to have better access to something like getting liquid nitrogen or dry ice than a teacher." Similarly, Astronomer 10 articulated, "I gathered all the equipment, all the materials and stuff and just covered the expenses." Likewise, Astronomer 1 commented, "I always wind up going to the Home Depot and buying stuff there."

Astronomers also frequently described characteristics of effective educator partners. Astronomers frequently mentioned that their educator partners were responsible for managing the classroom and students. For example, Astronomer 9 acknowledged, "She managed behavior because that was actually the thing I struggle with the most in terms of the experience." Teachers also mentioned that their main role was to manage students. Teacher 8 explained, "It's not fair to expect an astronomer to be disciplinarian. If you come with that attitude, the kids will be turned off, so let the teacher be the disciplinarian." Likewise, Teacher 5 stated, "I was there to address any discipline problems." Only a few teachers mentioned that to be an effective educator partner, they should be the ones "differentiating lessons and activities for kids that were average, or a little below average." Only one teacher mentioned administering pre or post astronomy assessments to students before and after their astronomer partner visits. 


\section{Astronomer and teacher dispositions}

The most frequently mentioned disposition that effective astronomer partners exhibited was an ability to relate to kids. Many teachers expressed that astronomers that know how to relate to kids "knew their names," "were excited," "passionate about what they do," "were knowledgeable," "felt comfortable around kids," "were tolerant," and were "easy going." For example, Teacher 6 articulated, "He knew how to handle the children and I didn't have to do that much discipline at all, which was pleasing to me." Astronomers without prior outreach experience expressed learning about how to relate with kids better. Two astronomer partners mentioned that they "got to see where kids were coming from" and were then able to "share their life experiences" with these students. Astronomer 4 remarked that "the astronomer has to gear their mindset toward whatever age group they're working with." Teacher 4 further mentioned that astronomers are "prompt."

Approximately $25 \%$ of astronomers mentioned that effective teacher partners are "committed," "motivated to have an astronomer in their classroom," "passionate about teaching and about their students," and "knowledgeable about the astronomy curriculum."

\section{DISCUSSION AND CONCLUSION}

The purpose of this study was to examine astronomers' and teachers' belief about what constitutes effective astronomer-educator partnerships in formal urban middle school classrooms. The findings of this study provide a range of beliefs and revealed that astronomers and teachers believed that establishing a relationship; maintaining communication; planning, preparing, and facilitating lessons collaboratively; and following up on lessons taught and modifying lessons for future implementation were vital characteristics for effective astronomer-educator partnerships. The study's findings also characterized effective astronomer partners as being willing to volunteer their time, willing to provide resources, and willing to purchase supplies, and effective educator partners as being responsible for managing the classroom and students, differentiating lessons and activities, and administering pre- and postastronomy assessments to students before and after their astronomer partner visits. The findings of this study further described a range of dispositions of effective astronomer partners which include being prompt, able to relate to kids, exited, passionate about what they do, knowledgeable, tolerant, and easy going, as well as the dispositions of effective teacher partners as being committed, motivated to have a volunteer astronomer in their classroom, passionate about teaching and about their students, and knowledgeable about the astronomy curriculum.

Although a limitation of our study is that participants were only interviewed post-participation in Baltimore Project ASTRO, we believe that this study's findings contribute to the research literature and can help to provide a more comprehensive understanding of the characteristics of effective astronomer-educator partnerships in formal urban middle school science classrooms. However, it is important to mention that the transferability of the findings of this study to other settings, including rural settings or suburban settings will need to be judged as the reader examines the results in the context of specific circumstances of interest. It is important to note that this study produced a range of characteristics of effective astronomereducator partnerships in urban middle school science classrooms. However, the characterizations of partnership collaboration, astronomer and teacher characteristics, and astronomer and teacher dispositions discussed in this study are not intended to be an exhaustive checklist, but rather to be used as a tool to provide essential guidance to all who are interested in designing and facilitating such science educational outreach programming. Additionally, the literature base suggests that the construct of "partnership" implies direct benefit for all parties involved, and involves two or more people, each with expertise or skills to contribute, working toward a common goal [22]. Bearing this in mind, we hope that the findings of this study can spark dialog among scientists, astronomers, and educators to help improve science teaching and learning for all students.

\section{ACKNOWLEDGMENTS}

We would like to formally acknowledge support from the National Science Foundation (AST-0952923) and also thank the Maryland Space Grant Consortium, and the Jess and Mildred Fisher Foundation for supporting the Baltimore Project ASTRO program.
[1] A. L. Luehman and D. Markowitz, Science teachers' perceived benefits of an out-of-school enrichment programme: Identity needs and university affordances, Int. J. Sci. Educ. 29, 1133 (2007).
[2] R. J. Miranda, Urban middle-school science teachers' beliefs about the influence of their astronomer-educator partnerships on students' astronomy learner characteristics, Astron. Educ. Rev. 11, 010101-1 (2012). 
[3] M. C. Linn, L. Shear, P. Bell, and J. D. Slotta, Organizing principles for science education partnerships: Case studies of students' learning about rats in space and deformed frogs, Educ. Technol. Res. Dev. 47, 61 (1999).

[4] M. Munn, P. O. Skinner, L. Conn, H. G. Horsma, and P. Gregory, The involvement of genome researchers in high school science education, Genome Res. 9, 597 (1999).

[5] G. Wheeler, The wake-up call we dare not to ignore, Science 279, 1611 (1998).

[6] N. Brickhouse, Teacher beliefs about the nature of science and their relationship to classroom practice, J. Teach. Educ. 41, 53 (1990).

[7] C. Briscoe, The dynamic interactions among beliefs, role metaphors, and teaching practices: A case study of teacher change, Sci. Educ. 75, 185 (1991).

[8] L. Bryan, Nestedness of beliefs: examining a prospective elementary teacher's belief system about science teaching and learning, J. Res. Sci. Teach. 40, 835 (2003).

[9] J. Nespor, The role of beliefs in the practice of teaching, J. Curric. Stud. 19, 317 (1987).

[10] M. Pajares, Teachers' beliefs and educational research: cleaning up a messy construct, Rev. Educ. Res. 62, 307 (1992).

[11] L. Bryan and M. Atwater, Teacher beliefs and cultural models: A challenge for science teacher education programs, Sci. Educ. 86, 821 (2002).

[12] S. R. Herwitz and M. Guerra, Perspectives, partnerships, and values in science education: A university and public elementary school collaboration, Sci. Educ. 80, 21 (1996).
[13] R. J. Miranda, Urban public high school teachers' beliefs about science learner characteristics: Implications for curriculum, Urban Educ. 41, 506 (2006).

[14] R. J. Miranda, Urban middle school teachers' beliefs about science learner characteristics: Implications for astronomy curriculum, Astron. Educ. Rev. 9, 010117-1 (2010).

[15] F. J. Rutherford and A. Ahlgren, Science for All Americans (Oxford University Press, New York, 1990).

[16] M. G. Gibbs and M. Berendson, Effectiveness of amateur astronomers as informal science educators, Astron. Educ. Rev. 5, 114 (2007).

[17] A. Fraknoi, M. Bennett, and J. Richter, Project ASTRO: A successful model for Astronomer/Teacher partnerships in New Trends in Astronomy Teaching edited by L. Gougeuenheim, D. McNally, and J. R. Percy (Cambridge University Press, Cambridge, England, 1998).

[18] L. P. Connolly, NAS Gives Rise to ASTRO, Mercury 26, 6 (1997).

[19] M. Patton, Qualitative Evaluation and Research Methods (Sage, Newbury Park, CA, 1990).

[20] J. P. Spradley, The Ethnographic Interview (Holt, Rinehart, \& Winston, New York, 1979).

[21] J. M. Corbin and A. L. Strauss, Basics of Qualitative Research: Techniques and Procedures for Developing Grounded Theory (Sage, United Kingdom 2008).

[22] D. Tomanek, Building successful partnerships between K-12 and universities, Cell Biol. Educ. 4, 28 (2005). 